\title{
UNA CRITICA DEL PROFESOR VELARDE
}

JAVIER TUSELL
UNED

He visto con interés la extensa nota crítica que el profesor Velarde dedica a mi libro Radiografía de un golpe de Estado. El ascenso al poder del general Primo de Rivera. La verdad es que el interés ha ido menguando a medida que pasaba sus páginas y debo decir que en la última he llegado a preguntarme si valía la pena responder a quien con tantas páginas me argüía con tan poca sustancia. Pero he pensado que es una excelente costumbre en la comunidad científica de otras latitudes la polémica y que no puede perderse la menor oportunidad de practicarla en España. Trataré, por tanto, de responderle con brevedad y de manera concreta.

$\mathrm{Al}$ parecer, hay cuatro cuestiones que en principio han llamado la atención del profesor Velarde respecto del contenido de mi libro. Paso a enumerarlas $y$, de paso, a darle respuesta:

1. La cuestión Alba. Cito algún documento que prueba que en determinados sectores había una profunda animadversión contra él; de ningún modo digo que yo esté de acuerdo en las calumnias de los libelos que circulaban. El profesor Velarde da la sensación de que piensa que el catalanismo es puro proteccionismo arancelario. Presentar, como hace, el golpe de Primo de Rivera como un golpe promovido por un catalanismo que engañó a un general contradice toda la documentación existente: la que antes había sido aportada y la que utilizo yo en mi libro. La interpretación de Velarde tiene la ventaja de la comodidad: no es necesario ningún documento para probarla porque es un absoluto a priori.

2. La cuestión Puig $i$ Cadafalch. De nuevo la tesis del profesor Velarde consiste en culpar al catalanismo, por vía de este personaje, del golpe. Me hubiera gustado investigar más la relación entre el catalanismo y Primo de Rivera, pero más me gustaría aún que, ya que yo no he conseguido otras fuentes, el profesor Velarde las aportara en vez de partir de otro a priori. De momento le recomiendo la lectura de las memorias de Puig i Cadafalch publicadas en La Veu de Catalunya, en febrero de 1930, que, obviamente, des- 
conoce. Es aterrador que alguien atribuya a un abrazo el amplisimo significado que le da Velarde: a base de esas simplificaciones uno puede hacer la Historia que quiera.

3. La cuestión Flores de Lemus. El profesor Velarde no entiende el giro que en un momento se produjo en el golpe de Primo de Rivera. Había hablado éste con el resto de los militares conspirados de un gobierno de civiles, entre los que alguno citó a Flores de Lemus. Creo haber probado -entre otras fuentes lo afirman las propias memorias de Primo de Rivera- que ese gobierno se convirtió en militar, en su pensamiento, durante el viaje de Madrid a Barcelona. En mi opinión, llegado a Madrid, ni siquiera le propuso a ningún civil formar parte de su gobierno; eso es lo malo de los golpes militares: que comienzan con un propósito y concluyen con otro. Dice el profesor Velarde que Flores de Lemus no quiso aceptar el nombramiento que se le propuso; como siempre, no da argumentos' ni siquiera para probar la propuesta. Anoto la sugerencia de hacer la historia de los golpes de Estado leyendo la Gaceta de Madrid; es algo así como historiar la revolución rusa con el Alcubilla.

4. La cuestión Suárez Inclán. Velarde me atribuye confundir a Miguel con Francisco Villanueva: es un error imputable no a mí, sino al confeccionador del índice onomástico. Me atribuye otro error en que confieso haber caído: el de confundir a Félix Suárez Inclán, ministro de Hacienda, con un general de división del mismo apellido de guarnición en Madrid. El profesor Velarde no parece tampoco saber el nombre de ese general, a pesar de sus sólidos conocimientos sobre linajes asturianos. Se llamaba Pío Suárez Inclán; el motivo de mi equivocación reside en que la fuente que he utilizado (las actas de la comisión de responsabilidades) le mencionan simplemente como «general Suárez Inclán» en una ocasión después de aducir el testimonio de los ministros. Además, se da la circunstancia, al parecer también ignorada por Velarde, de que Pío Suárez Inclán era también político (fue, por ejemplo, diputado por Baza, en Granada) y del mismo grupo garciprietista que el ministro, lo que colaboró a mi confusión. Agradezco la oportunidad de rectificar el error; afecta exactamente a siete líneas de mi libro.

Solventadas estas cuatro cuestiones, verdaderamente diminutas y que a lo sumo rozan tangencialmente la línea argumental de mi libro, quisiera añadir algunas reflexiones más.

El profesor Velarde se despacha contra mi modo de escribir; algo podría yo decir del suyo, pero me parece una pérdida de tiempo. Quisiera, sin embargo, decirle que juzgar a un libro por los errores de su índice onomástico es algo que no se hace desde los tiempos de las «trincas». Puedo decir que, 
por ejemplo, él ha prologado un libro en que mi modesto nombre aparece confundido con el de mi abuelo, teniente de alcalde de Barcelona por Lliga Catalana hasta que lo echó Primo de Rivera; nunca se me pasará por la cabeza hacerle ningún reproche. Me atribuye una falta de ortografía de un telegrama: como es lógico no la hice desaparecer, como tampoco di forma literaria al telegrama mismo. López Ochoa aparece como López de Ochoa de nuevo como consecuencia de un error del confeccionador del índice onomástico.

En segundo lugar, el profesor Velarde es un optimista al titular su nota «Puntualizaciones sobre un golpe de Estado». En realidad, lo único que me puntualiza es un error acerca de un general de guarnición en Madrid por aquellos días y un ministro que desempeñó un papel mínimo en los sucesos. La verdad es que ponerse tan paternal y ejercer de maestro que, desde la senectud, aconseja a principiantes para concluir en eso resulta un tanto chocante. Lo peor del caso es que hay muchas cosas discutibles en mi libro, al menos desde mi punto de vista, pero están eludidas en las páginas de Velarde. El decidió en su día que el rey y el catalanismo no eran los culpables del golpe; ya puede uno investigar, haciendo un voluminoso acopio de fuentes, que eso no le hará cambiar de opinión.

En tercer lugar, el profesor Velarde alude despectivamente a que en el libro se usa la documentación del archivo de Primo de Rivera y «alguna cosa más». Ese «alguna cosa más» consiste en los archivos de Alba, Portela Valladares, Maura y Natalio Rivas, los de Presidencia de Gobierno, Ministerio de la Gobernación y de las Cortes, aparte de la prensa madrileña y la barcelonesa, los diarios de sesiones del Congreso y del Senado, la bibliografía impresa y el archivo del Foreign Office. Si el profesor Velarde no ha visto esas fuentes en mi libro no es porque yo lo haya escrito demasiado deprisa, sino porque quizá tiene un afán demasiado posesivo acerca de la época, sobre la que escribió en el pasado. Me parece muy bien, pero sería todavía mejor que manejara también esas fuentes antes de emitir cualquier opinión.

Para concluir, quisiera añadir que de mis maestros aprendí a agotar las fuentes a la hora de hacer una investigación, pero también dos cosas más. En primer lugar, a no pontificar sobre lo que no se sabe: a mí no se me va a ocurrir debatir la tesis del prekeynesianismo de Primo de Rivera defendida por Velarde, aunque bien curiosa me parece. Yo creo que él debiera pensar serenamente si tiene la formación y el conocimiento para intentar pontificar en historia política para luego quedarse en casi nada. Además, no se debe sustituir la ignorancia real por un vago ensayismo producto de la particular ideología de uno. En mi opinión, eso es exactamente lo que hace el profesor Velarde con sus elucubraciones acerca del catalanismo. 